\title{
Electroluminescence powdered ZnS:Cu obtained by one-stage synthesis
}

\author{
Yu.Yu. Bacherikov ${ }^{*}$, A.G. Zhuk ${ }^{1}$, O.B. Okhrimenko ${ }^{1}$, D.L. Kardashov ${ }^{2}$, S.V. Kozitskiy ${ }^{2}$ \\ ${ }^{I} V$. Lashkaryov Institute of Semiconductor Physics, NAS of Ukraine \\ 41, prospect Nauky,03028Kyiv, Ukraine; *e-mail: Yuyu@isp.kiev.ua \\ ${ }^{2}$ Odessa National Maritime Academy, 8, Didrikhson str., 65029 Odessa, Ukraine
}

\begin{abstract}
Photo- and electroluminescence properties of $\mathrm{ZnS}$ obtained using selfpropagating high-temperature synthesis and doped with $\mathrm{Cu}$ were studied in this work. It has been shown that high-temperature one-stage synthesis enables to obtain two-phase system $\mathrm{ZnS}-\mathrm{Cu}_{2-\mathrm{x}} \mathrm{S}$ with the maximum radiation $515 \mathrm{~nm}$ for photo- and electroluminescence. Since the synthesis process is non-equilibrium, impurities distribute nonuniformly in the bulk of microcrystals. Additional annealing and introducing the Ga coactivator lead to more non-uniform distribution of impurities in the bulk of microcrystals. It causes the increase in the intensity of the blue band in photoluminescence spectra and shift of the maximum of electroluminescence toward longer wavelengths. It is probable that this increase in the intensity of the blue band in photoluminescence spectra is caused by formation of the radiative centers $\mathrm{Cu}_{\mathrm{i}}-\mathrm{Cu}_{\mathrm{Zn}}$.
\end{abstract}

Keywords: electroluminescence, photoluminescence, zinc sulfide, self-propagating hightemperature synthesis.

Manuscript received 08.04.15; revised version received 10.06.15; accepted for publication 03.09.15; published online 30.09.15.

\section{Introduction}

Recently, luminophors are being increasingly used in various semiconductor devices and information displays. Basic requirements for luminescent light sources are effective conversion of exciting radiation energy into the visible light energy, stable radiation in a given spectral range and low power consumption. One of the most technologically simple devices based on the phenomenon of electroluminescence (EL) is an electroluminescent capacitor based on powder electroluminophors. The advantage of these devices lies in the possibility to create them flexible, which allows expanding their application field.

One of the conditions, under which glowing electroluminophors activated with copper is possible at excitation with alternating electric field, is the existence of another phase inclusions in luminophor material, which allows creation of conditions for concentration of the field in thin layers of the sample. In ZnS-based electroluminophors, this condition is fulfilled by introducing a high concentration of copper (approximately $10^{-3} \mathrm{~g}$ of $\mathrm{Cu}$ per $1 \mathrm{~g}$ of $\mathrm{ZnS}$ ).

As it was ascertained in [1], for radiative recombination in semiconductors, in addition to recombination centers, it takes free electrons and holes, generation of which occurs through the existence of surface phase. In zinc-sulfide electroluminophors, the surface phase is copper sulfide, so excitation of electroluminophors is a number of processes of injection and multiplication of charge carriers in the heterojunction $\mathrm{ZnS}-\mathrm{Cu}_{2-\mathrm{x}} \mathrm{S}$. The bandgap of $\mathrm{Cu}_{2-\mathrm{x}} \mathrm{S}$ is much smaller and conductivity is much higher than those in $\mathrm{ZnS}$, that's why many researchers identify this contact 
with the Mott-Schottky type contact [2,3]. Depending on the ratios of the electron affinity energies, location of the Fermi levels and extent of doping materials forming heterojunctions $\mathrm{Cu}_{2-\mathrm{x}} \mathrm{S}-\mathrm{ZnS}: \mathrm{Cu}$, their energy diagrams and character of current flow will be different.

Whereas self-propagating high-temperature synthesis (SHS) is a low-cost technology, the use of this method allows to reduce the price obtained material. Besides, non-equilibrium of crystallization process allows obtaining the samples doped with impurities, concentration of which exceeds the equilibrium one [4]. Therefore, the possibility to obtain electroluminophors based on $\mathrm{ZnS}$ by using SHS method is an urgent task.

The aim of this work was to study the possibility of getting electroluminophor $\mathrm{ZnS}: \mathrm{Cu}$ by using the SHS method as well as to determine the effect of Ga impurity and subsequent thermal treatments on its spectral characteristics.

\section{Experimental technique}

The modes of synthesis were chosen in such a manner that allowed obtaining powdered $\mathrm{ZnS}$ doped with different impurities. For the samples synthesized by us, the content of starting materials was: $\mathrm{Zn}-0.45$ mole, $\mathrm{S}$ - 0.56 mole, $\mathrm{CuCl}-0.06$ mole, $\mathrm{Ga}-0.0025$ mole. Thermal annealing at $800{ }^{\circ} \mathrm{C}$ was performed in a laboratory silica furnace. Introduction of atmosphere gases to the annealed powder was limited by a gas gate of granular coal. The temperature mode of annealing process was controlled with a thermocouple, located in the area of annealed material. The annealing time was $120 \mathrm{~min}$.

The spectra of photoluminescence (PL) and electroluminescence (EL) were measured using the facility SDL-2 at room temperature. Excitation of PL was carried out using radiation of the nitrogen laser LHI-21 $(\lambda=337.1 \mathrm{~nm})$, and EL - alternating sinusoidal voltage $(U=0 \ldots 300 \mathrm{~V}, f=100 \ldots 5000 \mathrm{~Hz})$. To investigate EL, we used the device for express analysis of luminophors, as described in [5].

\section{Experimental results and discussion}

Photoluminescence spectra of powdered $\mathrm{ZnS}: \mathrm{Cu}, \mathrm{Cl}$ and $\mathrm{ZnS}: \mathrm{Cu}, \mathrm{Ga}$ synthesized by SHS method are presented in Fig. 1. The amount of copper introduced into furnace charge was sufficient for doping $\mathrm{ZnS}$ and formation of the phase $\mathrm{Cu}_{2} \mathrm{~S}$ necessary for creating the heterojunction $\mathrm{Cu}_{2-\mathrm{x}} \mathrm{S}-\mathrm{ZnS}$. As shown in Fig. 1, the PL spectra are quite different from each other. If the PL spectrum for the powder $\mathrm{ZnS}: \mathrm{Cu}, \mathrm{Cl}$ is a broad band in the blue-green spectral range with $\lambda_{\max } \sim 515 \mathrm{~nm}$, the PL spectra for $\mathrm{ZnS}: \mathrm{Cu}, \mathrm{Ga}$ before and after annealing consist of two broad bands with $\lambda_{\max } \sim 440 \ldots 450 \mathrm{~nm}$ and $\lambda_{\max } \sim$ $515 \ldots 535 \mathrm{~nm}$. The difference between the PL spectra of $\mathrm{ZnS}: \mathrm{Cu}$, Ga before and after annealing is revealed in the ratio of intensities of blue and green bands.
Fig. 2 shows the EL spectra for powders $\mathrm{ZnS}: \mathrm{Cu}, \mathrm{Cl}$ (curve 1) and $\mathrm{ZnS}: \mathrm{Cu}, \mathrm{Ga}$ (curve 2) as well as $\mathrm{ZnS}: \mathrm{Cu}, \mathrm{Ga}$ annealed at $400{ }^{\circ} \mathrm{C}$ (curve 3). As shown in Fig. 2, the EL spectra have the form of broad bands in the blue-green spectral range with the peaks at $\lambda_{\max } \sim 515 \mathrm{~nm}, \sim 525 \mathrm{~nm}, \sim 535 \mathrm{~nm}$, respectively, for the curves 1,2 and 3. Thus, introduction of Ga leads to flaring up the blue PL band and shifting the green band into the long-wave side. Additional annealing of $\mathrm{ZnS}: \mathrm{Cu}, \mathrm{Ga}$ led to further strong increasing the blue EL band and shifting the green band into the long-wave side. Additional annealing after synthesis leads to a more uniform distribution of $\mathrm{Cu}$ impurities in material, including that over the phase $\mathrm{Cu}_{2-\mathrm{x}} \mathrm{S}$. Annealing also promotes more active introduction of copper into lattice sites, the availability of co-activator $\mathrm{Ga}$ also contributes to this process. But account must be taken of that the synthesis of material occurs in a relatively short period of time (several minutes), and the temperature in this time period ranges from 300 up to $2500 \ldots 3000 \mathrm{~K}$. Therefore, the impurity distribution, ratio of phases etc. are the result of non-equilibrium conditions for synthesis of material.

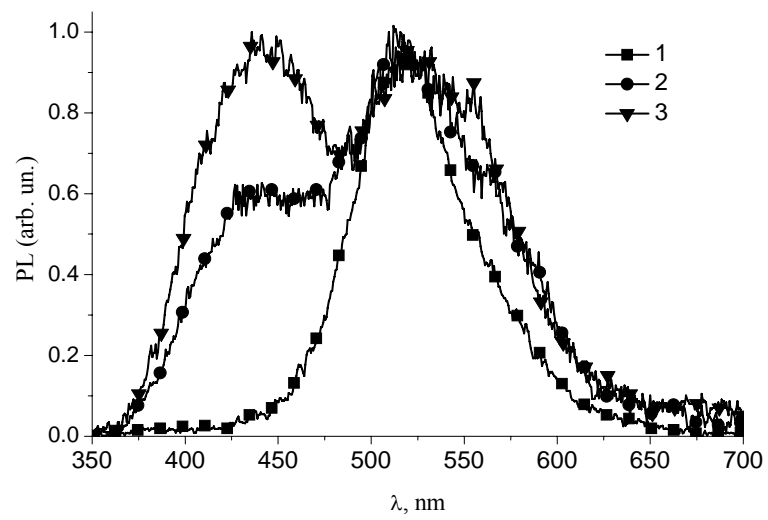

Fig. 1. Photoluminescence spectra of luminophors $\mathrm{ZnS}: \mathrm{Cu}, \mathrm{Cl}$ (1) and $\mathrm{ZnS}: \mathrm{Cu}, \mathrm{Ga}(2)$ as well as luminophor $\mathrm{ZnS}: \mathrm{Cu}, \mathrm{Ga}$ annealed at $400{ }^{\circ} \mathrm{C}(3) . \lambda=337.1 \mathrm{~nm}$ of the nitrogen laser LHI-21.

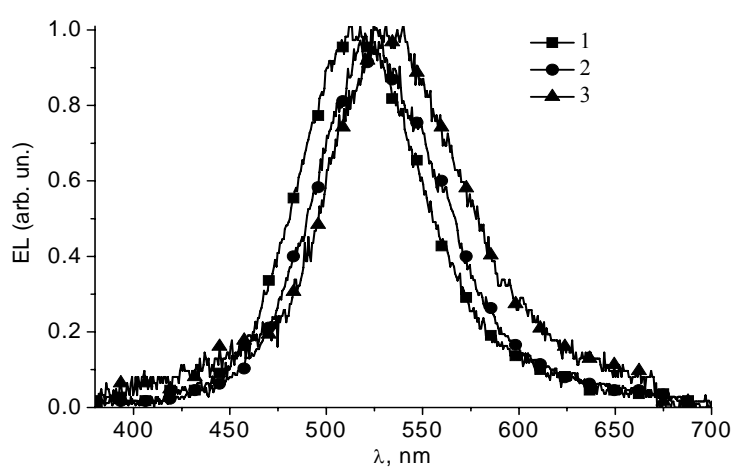

Fig. 2. EL spectra of luminophors $\mathrm{ZnS}: \mathrm{Cu}, \mathrm{Cl}$ (1) and $\mathrm{ZnS}: \mathrm{Cu}, \mathrm{Ga}(2)$ as well as luminophor $\mathrm{ZnS}: \mathrm{Cu}, \mathrm{Ga}$ annealed at $400{ }^{\circ} \mathrm{C}(3)$. 
Effect of $\mathrm{Ga}$ as a co-activator on the spectral composition and intensity of PL is related with the need to compensate the charge of internal defects in material, which is described in many details in [6-8]. In [8], it was shown that even a small amount of Ga impurities in $\mathrm{ZnS}$ promotes introducing copper into specific sites of sublattice or filling $\mathrm{Zn}$ vacancies, which leads to increasing contribution of the green band in the luminescence spectrum. The appearance of the blue band in the PL spectrum when introducing Ga (Fig. 1, curves 2 and 3 ) is related, apparently, with formation of centers of close DA pair of the $\mathrm{Cu}_{\mathrm{i}}-\mathrm{Cu}_{\mathrm{Zn}}$ type.

The increase in intensity of the blue band (Fig. 1, curve 3) is likely related with redistribution of copper impurity in the bulk of microcrystals. And the presence of $\mathrm{Ga}$ as co-activator, which along with copper fills the place in the cation sublattice, leads to additional association of copper ions and formation of centers of close DA pair of the $\mathrm{Cu}_{\mathrm{i}}-\mathrm{Cu}_{\mathrm{Zn}}$ type and, accordingly, to the increase in the blue band of photoluminescence.

\section{Conclusions}

As seen from the results, the SHS method enables to obtain two-phase systems. Account must be taken that SHS is non-equilibrium process, which leads to nonuniform distribution of impurities and simultaneous formation of different phases of the obtained material. Considering the peculiarities of synthesis and need to obtain two phases, copper was introduced in some excess amount during the process of preparing the furnace charge. The excess is necessary, on the one hand, for doping of zinc sulfide, and on the other hand, for formation of the phase $\mathrm{Cu}_{2-\mathrm{x}} \mathrm{S}$.

\section{References}

1. P.K. Srivastava, D. K. Chakraborty, K.K. Jain, P.S. Chowdhary, The electroluminescence (EL) and photoluminescence (PL) spectra of $\mathrm{ZnS}$ : $\mathrm{Cu}, \mathrm{Cl}$ (cubic and hexagonal) phosphors // J. Chem. Bio. Phys. Sci. Sec. C, 4(3) p. 3573-3577 (2014).

2. Sang-Do Hana, Ishwar Singhb, Devender Singhb, You-He Leea, Gaytri Sharmaa, Chi-Hwan Hana, Crystal growth of electroluminescent $\mathrm{ZnS}: \mathrm{Cu}, \mathrm{Cl}$ phosphor and its $\mathrm{TiO}_{2}$ coating by sol-gel method for thick-film EL device // J. Lumin. 115(3-4), p. 97-103 (2005).

3. M. Warkentin, F. Bridges, S.A. Carter, and M. Anderson, Electroluminescence materials $\mathrm{ZnS}: \mathrm{Cu}, \mathrm{Cl}$ and $\mathrm{ZnS}: \mathrm{Cu}, \mathrm{Mn}, \mathrm{Cl}$ studied by EXAFS spectroscopy // Phys. Rev. B, 75, 075301 (2007).

4. S.V. Kozyts'ky, Obtaining ZnSe by the method of self-propagating high-temperature synthesis // Fizika khimiia tverdogo tela, 4(2), p. 229 (2003), in Russian.

5. Yu.Yu. Bacherikov, S.V. Optasiuk, V.E. Rodionov, M.O. Mukhlio, O.T. Kheilenko, Device for express analysis // Patent № 67988 A, H05B33/12, G01N27/00; Publ. 15.07.2004, Bull. №7.

6. M. Aven, D.S. Prener, Physics and Chemistry of $A^{2} B^{6}$ Compounds. Mir, Moscow, 1970 (in Russian).

7. N.K. Morozova, V.A. Kuznetsov, Zinc Sulfide. Obtaining and Optical Properties. Nauka, Moscow, 1987 (in Russian).

8. J. Stanley, Yu Jiang, F. Bridges, S. A. Carter, Laurel Ruhlen, Degradation and rejuvenation studies of AC electroluminescent $\mathrm{ZnS}: \mathrm{Cu}, \mathrm{Cl}$ phosphors // J. Phys.: Condens. Matter, 22(5) 055301. doi:10.1088/09538984/22/5/055301 (2010). 